\title{
FÁCIES GLACIOCONTINENTAIS (OUTWASH PLAIN) NA MEGASSEQUÊNCIA MACAÚBAS ,(SERRA DA ÁGUA FRIA/MG) E SEU CONTEXTO TECTÔNICO
}

\author{
MARCELO A. MARTINS-NETO*, NEWTON SOUZA GOMES, CÍZIA M. HERCOS \& LUCIANA A. REIS
}

\begin{abstract}
GLACIOCONTINENTAL FÁCIES (OUTWASH PLAIN) IN THE MACAÚBAS MEGASEQUENCE (SERRA DA ÁGUA FRIA/MG) MEGASEQUENCE AND ITS TECTONIC CONTEXT This paper presents the results of integrated studies on sedimentary fácies, depositional architecture, sedimentary petrology and paleogeography, carried out in sandstones associated with the Jequitaí diamictites. These rocks belong to the base of the Macaúbas Megasequence and crop out in the Serra da Agua Fria, in the central-north part of Minas Gerais State. The data allow to interpret the studied deposits as a product of a proglacial outwash plain sustem, which has evolved in the NNE direction. These paleocurrent data, analysed together with data from the western border of the Serra da Agua Fria, indicate the existence of a sindepositional structural high in the Serra da Agua Fria area, which, under the action of glaciers and seasonal cycles of melt-water, had supplied sediments (most probably from a source área in the Espinhaço rocks) towards a structural low located to the west. This paleogeography is related to the Early Neoproterozoic rift extensional tectonics responsible for the development of the Macaúbas/Salinas basin. Although many authors had stated that the Jequitaí glaciation was of a continental type with eastward moving glaciers, we interpret that this glaciation as a rift-shoulder related, altitude model. The paleocurrent data achieved in the Serra da Água Fria área show sediment dispersion towards the interior of the São Francisco Craton and from this area towards a NNE direction.
\end{abstract}

Keywords:M\&caúbas Megasequence, Neoproterozoic, Sedimentation, Tectonics, Basin Analysis.

RESUMO Este trabalho apresenta os resultados da integração de estudos de fácies sedimentares, arquitetura deposicional, petrologia sedimentar e paleogeografia em arenitos associados aos diamictitos Jequitaí, pertencentes à base da Megaseqüência Macaúbas, aflorantes na Serra da Agua Fria, centro-norte de Minas Gerais. Os dados apresentados permitem interpretar os depósitos estudados como produtos de um sistema fluvial entrelaçado proglacial (outwash plairi), que evoluiu na direcão NNE. Os dados de paleocorrente, quando analisados em conjunto com dados relativos à borda oeste da Serra da Agua Fria, indicam a existência de um alto estrutural sindeposicional na região da Serra da Agua Fria que, sob a atuação de geleiras e de ciclos sazonais de gelo e degelo, forneceu os sedimentos (a maioria provavelmente oriunda de rochas do Espinhaço) para uma região baixa situada a oeste da mesma. Esta paleogeografia estaria ligada à tectônica extensional riftogênica do início do Neoproterozóico, que levou ao desenvolvimento da Bacia Macaúbas/Salinas. Embora muitos autores interpretem a glaciação Jequitaí como do tipo continental com geleiras movendo-se para leste, nós interpretamos a glaciação Jequitaí sob um modelo de altitude, relacionado ao soerguimento de ombreiras de rifte. Os dados de paleocorrente na região da Serra da Agua Fria mostram que, nesta região, houve dispersão de sedimentos em direção ao interior do Craton do São Francisco e daí para NNE.

Palavras-chaves: Megassequiência Macaúbas, Neoproterozóico, Sedimentação, Tectônica, Análise de Bacias

INTRODUÇÃO Embora existam trabalhos que abordam sobre a evolução sedimentar da Megasseqüência Macaúbas tanto nos domínios do Craton do São Francisco quanto da Faixa Araçuaí (p. ex. Uhlein 1991, Trompette 1994), depósitos verdadeiramente glaciocontinentais ainda não foram devidamente caracterizados nesta unidade. A caracterização destes depósitos e, sobretudo, de seu contexto paleogeográfico constituem passos importantes no entendimento do início da sedimentação neoproterozóica na região do Craton do São Francisco e faixas móveis adjacentes. O termo "Megasseqüência" é utilizado no sentido de Hubbart et al (1985), significando uma unidade estratigráfica limitada por importantes descontinuidades regionais englobando depósitos relativos a um ciclo bacinal completo.

Utilizando métodos variados tais como estudo de fácies sedimentares, análise da arquitetura deposicional e petrologia sedimentar, este trabalho tem como objetivo caracterizar depósitos de planície fluvial proglacial (outwash plain) existentes na Megasseqüência Macaúbas. O afloramento estudado em detalhe, com aproximadamente $120 \mathrm{~m}$ de exposicão contínua, localiza-se às margens da $\mathrm{Br} 365$, a $23 \mathrm{~km}$ do trevo de Jequitaí em direção a Montes Claros (Fig. 1). A contextualização paleogeográfica destes depósitos e de suas unidades associadas permitiu uma melhor caracterização da ambiência tectônica sindeposicional da base da Megasseqüência Macaúbas.

CONTEXTO REGIONAL Três ciclos bacinais caracterizam a evolução proterozóica da porção leste do Craton do São Francisco e zona externa da Faixa Araçuaí, representados pelas megasseqüências Espinhaco, Macaúbas e Bambuí (Fig. 2, Fig. 3), que correspondem na litoestratigrafia, respectivamente, ao Supergrupo e Grupos homónimos.

A integração de estudos sedimentológicos, paleogeográficos, estratigráficos e tectônicos (sintetizados em Martins-Neto 1998) indica que a evolução estratigráfica da Bacia Espinhaço, de idade paleo/mesoproterozóica, foi basicamente controlada pela sua história de subsidência, permitindo a subdivisão da Megasseqüência Espinhaço, em seis tectonosseqüências (TS) denominadas (Martins-Neto 1995a, 1995b): Olaria, Natureza, São João da Chapada, Sopa-Brumadinho, Galho do Miguel e Conselheiro Mata. A TS Olaria representa o registro da fase pré-rifte da bacia, as TS's Natureza, São João da Chapada e Sopa-Brumadinho o registro da fase rifte, a TS Galho do-Miguel o registro da fase transicional e a TS Conselheiro Mata o registro da fase flexural. Cada tectonosseqüência inclui os depósitos de uma associação de sistemas deposicionais (linked depositional systems), acumulados durante uma fase tectônica específica da bacia, sendo limitada por importantes descontinuidades regionais. Estas discordâncias marcam importantes etapas na reorganização paleogeográfica da bacia. Durante a fase rifte, processos de subsidência mecânica devido ao adelgaçamento litosférico e ruptura da crosta por estiramento dominaram e controlaram a evolução estratigráfica da bacia. A evolução das fases transicional e flexural foi provavelmente controlada por processos de subsidência flexural térmica devido a contração termal (adensamento) da litosfera durante seu resfriamento. $\mathrm{O}$ estudo da evolução tectonosedimentar da Bacia Espinhaço Meridional permitiu sua caracterização como uma bacia do tipo rift-sag, ou seja, desenvolvida inteiramente em um contexto intracratônico (sem o desenvolvimento de centros de espalhamento oceânico), com um período de rifteamento inicial, seguido por um período flexural e consequente expansão em área da bacia (Martins-Neto 1998).

A deposição neoproterozóica na Bacia do São Francisco inicia-se com produtos glaciogênicos atribuídos à unidade litoestratigráfica denominada Formação Jequitá (Pflug \& Renger 1973, Karfunkel \& Hoppe 1988, Uhlein 1991, Uhlein et al. 1995, Martins-Neto et al. 1997a, 1997b, Hercos \& Martins-Neto 1997, Hercos 2000), pertencente à Megasseqüência Macaúbas (Martins-Neto et al. 1997a). Sobre os depósitos glaciogênicos e unidades associadas, ocorrem arenitos finos, siltitos, argilitos e margas, por vezes organizados em ritmitos, interpretados como depositados em sistema marinho raso (Hercos \& Martins-Neto 1997, Hercos 2000), que poderiam representar os produtos de uma transgressão glácio-eustática que encerra o tempo Macaúbas nos, domínios do Craton do São Francisco (MartinsNeto et al. 1997a). É notável o paleorelevo de origem erosiva que marca a descontinuidade no contato entre as megasseqüências Espinhaço e Macaúbas (Dupont 1996, Espinoza 1996, Martins-Neto et al 1997b). Estes depósitos se associam em direção a leste com a sucessão diamictítica/pelítica exposta na Faixa Araçuaí e, segundo PedrosaSoares (1995) e Uhlein et al. (1995), depositadas em uma bacia tipo rifte que teria evoluído, segundo o primeiro autor, para uma margem passiva (Bacia Macaúbas/Salinas).

Nos domínios do Craton do São Francisco, alguns autores (p. ex., Karfunkel \& Hoppe 1988, Uhlein 1991, Trompette 1994, Uhlein et al 1995) sugerem que a glaciação Jequitaí teria sido do tipo continental, com geleiras cobrindo vastas áreas e movimentando-se no sentido leste, em direção à Bacia Macaúbas/Salinas. Martins-Neto et al (1997a), com base no caráter erosivo em vales profundos da discordância Espinhaço/Macaúbas (indicando glaciação de altitude) e em diferentes espessuras do pacote glaciogênico e unidades associadas (sugerindo o papel de compartimentos da bacia com diferentes taxas de

Departamento de Geologia - Escola de Minas - Universidade Federal de Ouro Preto, Caixa Postal 173 - 35400-000 - Ouro Preto/MG, E-mail: neto@degeo.ufop.br 
subsidência controlando a sedimentação), propuseram um modelo riftogênico para a Glaciação Jequitaí/Macaúbas, onde as elevações topográficas geradas pelo soerguimento por rebate elástico das ombreiras dos grabens condicionaram a formação de geleiras, com os produtos destas e de sistemas deposicionais associados preenchendo os grabens.

A idade de deposição da Megasseqüência Macaúbas é de difícil determinação. As idades U-Pb de 1.000 Ma, obtidas em vulcânicas félsicas dacíticas e riolíticas interpretadas como produtos do início de extensão crustal (Brito Neves et al. 1993), de $906 \pm 2$ Ma, obtida em rochas básicas que cortam a Mégasseqüência Espinhaço (Machado et al. 1989) e de 900 Ma para zircões detrítieos retirados de diamictitos Jequitaí (Buchwaldt et al., 1999), determinam a idade máxima da deposição da unidade. A idade mínima pode ser sugerida pelo início do fechamento da Faixa Brasília marcado pela colocação dos granitos $44^{\circ} 30^{\circ}$ $44^{\circ} 00^{\circ}$

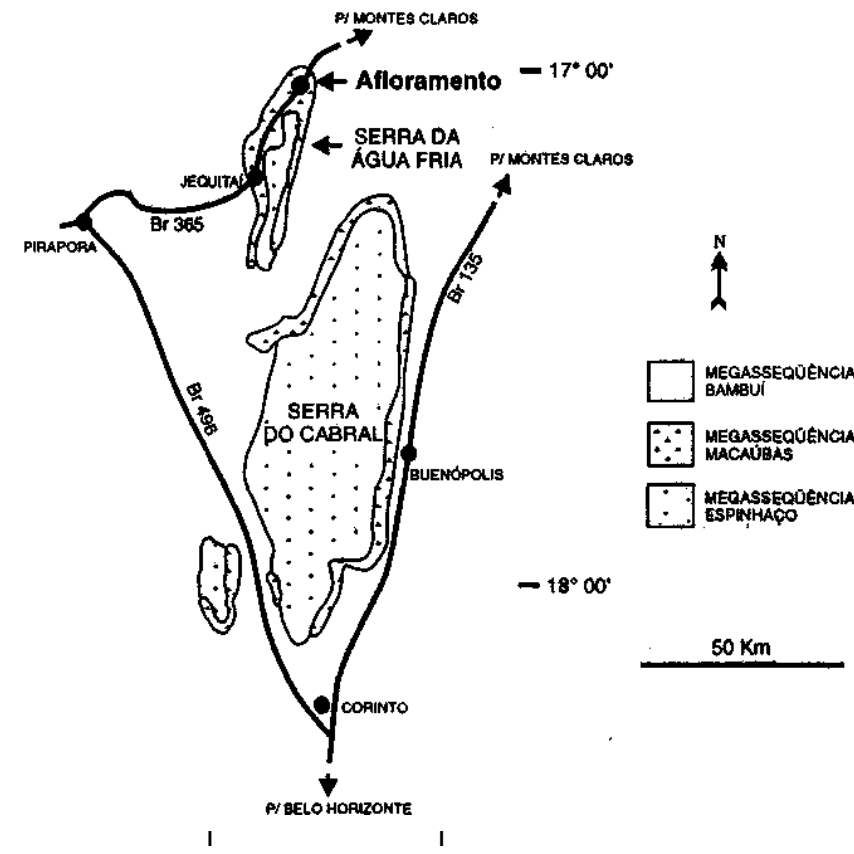

Figura l - Localização do afloramento estudado na porção norte da Serra da Água Fria, município de Jequitaí. Geologia modificada de Pedrosa-Soares et al. (1994).

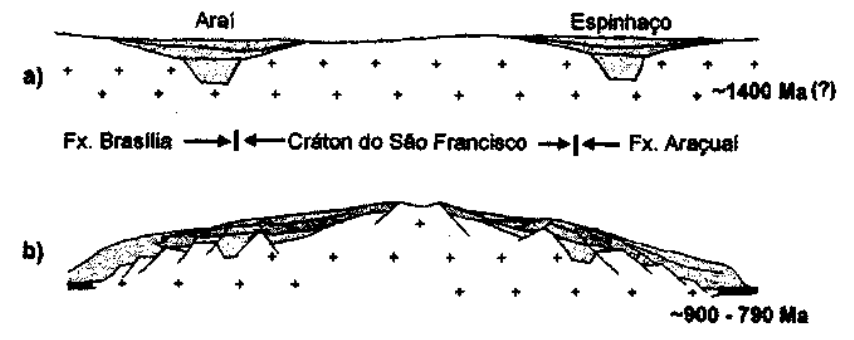

c)

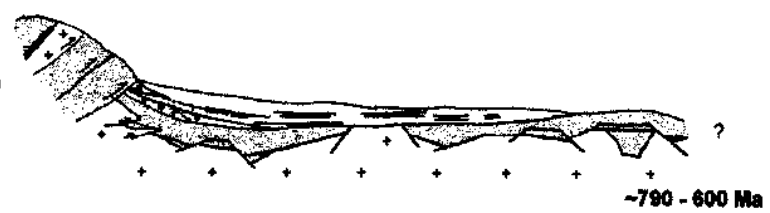

d)

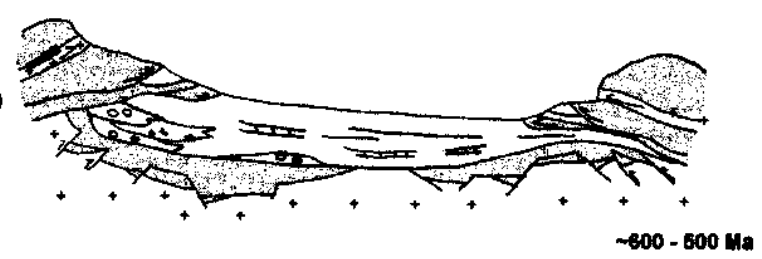

Figura 3 - Cenário evolutivo das coberturas neoproterozóicas do Cráton do São Francisco: a) situação no final da deposição nas bacias paleo/mesoproterozóicas (Espinhaço e Arai); b) deposição da Mégasseqüência Macaúbas em contexto extensional (tonalidade mais escura representa depósitos glaciogênicos, tonalidade mais clara representa depósitos marinhos pós-glaciais, cor preta representa crosta oceânica); c) deposição da Mégasseqüência Bambui em bacia "foreland" durante orogênese na Faixa Brasília; d) fase final da Bacia "Foreland" Bambuí, onde seus depósitos são deformados pelo fechamento da Faixa Araçuaí. Figura sem escala (modificado de Martins-Neto et al. 1997a).

\begin{tabular}{|c|c|c|c|c|c|c|}
\hline \multicolumn{2}{|c|}{ ESTRATIGRAFIA } & IDADE (Ma) & TTPO DE BACIA & REgIME TECTÔNICo & AMBIENTE DEPOSICIONAL & $\begin{array}{l}\text { REF. } \\
\text { BIBL. }\end{array}$ \\
\hline \multirow{2}{*}{$\begin{array}{l}\text { Megasseqüência } \\
\text { Bambứ }\end{array}$} & TS Tres Marias & -600 & \multirow{2}{*}{ Foreland } & \multirow{2}{*}{$\begin{array}{l}\text { Flexural por sobrecarga } \\
\text { tectônica }\end{array}$} & $\begin{array}{c}\text { Continental } \\
\text { Marinho Raso }\end{array}$ & 9,11 \\
\hline & TS Paraopeba & -790 & & & Marinho Raso & $7,11,12$ \\
\hline \multirow{3}{*}{$\begin{array}{l}\text { Megasseqüuência } \\
\text { Macaúbas }\end{array}$} & Paraconformidade a Dis & scordância Er & osiva (localmente & ngular) Ref.:13,14,15,16 & & \\
\hline & TS Superiot & -790 & \multirow{2}{*}{$\begin{array}{l}\text { Rifte-Margem } \\
\text { Passiva }\end{array}$} & Flexural/Termal & $\begin{array}{c}\text { Marinho } \\
\text { (subida glacio-eustática) }\end{array}$ & $8,16,19$ \\
\hline & TS Inferior & -900 & & Extensional & $\begin{array}{l}\text { Glacio-continental } \\
\text { Glacio-marinho }\end{array}$ & $\begin{array}{l}8,10 \\
16,18\end{array}$ \\
\hline \multirow{5}{*}{$\begin{array}{l}\text { Megasseqūência } \\
\text { Espinhaço }\end{array}$} & Discordância Prof & fundamente $E$ & rosiva (localmente & gular) Ref.:16,17,21,22 & & \\
\hline & $\begin{array}{l}\text { Fase Flexural } \\
\text { TS Conselheiro Mata }\end{array}$ & $1.500 ?$ & \multirow{4}{*}{ Rifte-Sag } & \multirow{2}{*}{ Flexural/Termal } & \multirow{2}{*}{$\begin{array}{l}\text { Marinho Raso } \\
\text { É́lico }\end{array}$} & 6,22 \\
\hline & $\begin{array}{c}\text { Fase Transicional } \\
\text { TS Galho do Miguel }\end{array}$ & & & & & 2,5 \\
\hline & $\begin{array}{c}\text { Fase Rifte } \\
\text { TS Sopa-Brumadinho } \\
\text { TS São João da Chapada } \\
\text { TS Natureza } \\
\end{array}$ & 1.715 & & \multirow[t]{2}{*}{ Extensional } & \multirow{2}{*}{$\begin{array}{l}\text { Leque aluvial } \\
\text { Fan-dejta } \\
\text { Lacustre } \\
\text { Fluvial } \\
\text { Eolico }\end{array}$} & $2,3,4$ \\
\hline & $\begin{array}{c}\text { Fase Pré-Rifte } \\
\text { TS Olaria }\end{array}$ & -1.750 & & & & 1 \\
\hline
\end{tabular}

1)Silva (1995); 2,3,4,5)Martins-Neto (1993,1994,1996a,1996b); 6,7)Dupont (1995,1996); 8)Hercos \& Martins-Neto (1997); 9)Chiavegatto (1992); 10)Uhlein (1991); 11)Dardenne (1978); 12)Schöll (1972); 13)Braun et al. (1993); 14)Teixeira et al, (1993); 15)Martins et al.(1993); 16,17,18)MartinsNeto et al. (1997a,1997b,1998); 19)Hercos (1999); 20)Romeiro Silva (1997); 21)Souza P (1995); 22)Espinoza (1996). 
sintectônicos da Sequência Maratá, datado de $794 \pm 10$ Ma (Pimentel et al. 1995).

Uma discordância de caráter regional separa a Megasseqüência Macaúbas da sobreposta Megasseqüência Bambuí (Martins-INeto et al. 1997a, Hercos 2000). O início da deposição Bambuí é marcado localmente por um conglomerado/diamictito basal, denominado Carrancas ou Samburá. As relações observadas na região SW do Cráton do São Francisco indicam que os conglomerados denominados Samburá foram formados a partir de fan-deltas cujos clastos são provenientes de rochas da Faixa Brasília situadas à oeste, estando, por vezes, assentados sobre os calcários Bambuí e sobre o embasamento (Castro 1997; Castro \& Dardenne 1995). Tais rochas não mostram aspectos que possam associá-las à uma origem glaciogênica. É marcante a continuidade lateral da Megasseqüência Bambuí ao longo de toda a extensão da sua bacia, bem como um espessamento deste pacote para oeste na direção da Faixa Brasília, indicando ter sido o depocentro da Bacia Bambuí junto desta faixa (Braun et al. 1993, 1996, Martins et al. 1993, Romeiro Silva 1997, Hercos 2000). Os dados sísmicos e de afloramento acima resumidos permitiram Castro \& Dardenne (1995) e Martins-Neto et al. (1997a) relacionar a sedimentação das rochas do Grupo Bambuí a um contexto de uma bacia foreland da Faixa Brasília, em função da continuidade dos processos erosivos na zona deformada e como resposta flexural da litosfera ao empilhamento rochoso na borda da área estável. $\mathrm{O}$ início da sedimentação Bambuí pode ser balizado em aproximadamente $790 \mathrm{Ma}$ (início do fechamento da Faixa Brasília), se estendendo até aproximadamente $600 \mathrm{Ma}$ (auge da deformação principal nas nappes da porção sul da faixa, cf. Valeriano 1992). A evolução da bacia foreland Bambuí antecede a orogênese da Faixa Araçuaí posto estarem deformados e metamorfizados os sedimentos da Megasseqüência Bambuí de modo similar ao apresentado nesta faixa (fechamento a partir de $600 \mathrm{Ma}$, cf. Trompette 1994). A Fig. 3 apresenta, esquematicamente, um provável cenário evolutivo para as coberturas neoproterozóicas do Cráton do São Francisco.

DESCRIÇÃO E INTERPRETAÇÃO DE FÁCIES Quatro fácies podem ser reconhecidas na seção levantada (Tabela 1 ):i) arenitos com estratificação/laminação plano-paralela, ii) arenitos com estratificação cruzada, iii) arenitos com laminação cruzada de ripples e iv) pelitos. A terminologia proposta por Miall (1978) é adotada para a classificação das fácies, acrescida da letra "P" para designar a fácies pelítica. Âs fácies são individualmente descritas e interpretadas neste item. As relacões espaciais entre as mesmas, incluindo trenas de proximidade/distalidade e ordenamento vertical, serão discutidas no item subsequente, denominado "arranjo espacial das fácies e arquitetura deposicional".

Arenitos com estratificação/laminação plano-paralela (Fácies Sh) A fácies Sh ocorre em corpos com geometria tabular e alta razão extensão lateral/espessura, ora exibindo estratificação ora laminação plano-paralela, organizados em sets com espessuras de ordem decimétrica, normalmente da ordem de 30 a $40 \mathrm{~cm}$. Cosets podem atingir até quase $1 \mathrm{~m}$ de espessura. A superfície do limite inferior dos cosets é sempre erosiva. A superficie limite inferior dos sets, quando bem caracterizada, é normalmente erosiva, caracterizando superficies erosivas internas nos cosets. A superficie superior pode ser também erosiva, sendo em outros casos gradacional para arenitos com estratificação cruzada, Texturalmente os arenitos são normalmente finos a médios, exibindo seleção moderada, e mostrando, localmente, níveis mais grossos e mal selecionados. Os grãos variam de bem arredondados a angulosos, predominando os tipos intermediários. As estruturas sedimentares presentes, o aspecto textural observado e a alta razão extensão lateral/espessura dos sets permitem, em conjunto, que esta fácies seja interpretada como produto de enxurradas em lençol em condições de pico de descarga sob regime de fluxo superior. Limites inferiores erosivos de sets provavelmente representam oscilações na potência do fluxo dentro de um mesmo evento agradacional.

\section{Arenitos com estratificação cruzada (Fácies St/Sp)}

Ocorrendo em corpos lenticulares com altas razões extensão lateral/espessura, esta fácies exibe sets com espessuras variando de 10 a $30 \mathrm{~cm}$ e cosets entre 30 e $70 \mathrm{~cm}$. Os arenitos, normalmente brancos a amarelados, são finos a médios e com seleção moderada. Os grãos, da mesma forma que na fácies anteriormente descrita, variam de bem arredondados a angulosos, predominando os tipos intermediários. Em função da seção analisada ser aproximadamente paralela à paleodirecão do fluxo, a caracterização do tipo de estratificacão cruzada é dificultada. Entretanto, a observação de superficies sub-ortogonais à seção principal em algumas fraturas $\mathrm{e} a$ alta tangencialidade à base dos foresets permitem inferir que, na grande maioria dos casos, tratam-se de estratificações cruzadas acanaladas (fácies St). Alguns foresets tabulares-planares atestam a presença local de estratificacõos cruzadas planares (fácies Sp). Localmente podem ser observadas estratificações cruzadas recumbentes (overturned cross-beds). Estas ocorrem bem desenvolvidas, são confinadas a um único set e truncadas, na sua porção superior, pela base não deformada do set sobreposto. A fácies St é interpretada como depositada através da migração de dunas 3-D subaquáticas (sensu Ashley 1990) em regime de fluxo inferior, enquanto a fácies Sp seria produto da migração de dunas 2-D.

\section{Arenitos com laminação cruzada de ripples (Fácies Sr)}

Esta fácies ocorre de forma subordinada em relação às anteriores. Ela é restrita a alguns corpos lenticulares de espessura centimétrica e alta razão extensão lateral/espessura, compostos por arenitos finos. Exibe internamente laminação cruzada, podendo ser interpretada como produto da migração de ripples de corrente na porção inferior do regime de fluxo inferior.

Pelitos (Fácies P) Níveis delgados (espessuras variando de milímetros a poucos centímetros) e em alguns casos lateralmente contínuos de pelitos ocorrem separando cosets de arenitos no afloramento estudado, sendo, em muitos casos, fundamentais para a distinção dos cosets. Estes níveis são constituídos por siltitos argilosos verde acinzentados. A observação direta dos níveis é muitas vezes prejudicada pela presença de veios de quartzo injetados nestas litologias. A fácies $\mathrm{P}$ é interpretada como depósitos de acresção vertical que capeiam os ciclos de decaimento progressivo de inundação (mud drapes).

ARRANJO ESPACJAL DAS FÁCIES E ARQUITETURA DEPOSICIONAI. Duas secões colunares foram levantadas no afloramento estudado, para representar o ordenamento vertical das fácies (Fig. 4). Em ambas as seções, o arranjo vertical das fácies permite a caracterização de ciclos de decaimento progressivo de inundação (waning-flood cycles) (Fig. 5), cada ciclo representando um evento deposicional/agradacional, caracterizado por diminuição gradativa de energia em direção ao topo. Um ciclo completo inicia-se com produtos de regime de fluxo superior (arenitos com estratificação/laminação plano-paralela da fácies Sh). Estes são seguidos por depósitos de regime de fluxo inferior, inicialmente com arenitos mostrando estratificacão cruzada da fácies $\mathrm{St} / \mathrm{Sp}$ (porção superior do regime de fluxo inferior) e, subsequentemente, por arenitos com laminação cruzada de ripple da fácies $\mathrm{Sr}$ (porção inferior do regime de fluxo inferior). $\mathrm{O}$ ciclo termina com depósitos de acresção vertical (pelitos da fácies P) que atestam o completo abatimento do fluxo. Entretanto, a maioria dos ciclos observados no campo se mostra incompleto (Fig. 4). Alguns ciclos não exibem a fácies Sh na base, sugerindo que toda sua evolução se deu sob regime de fluxo inferior. Outros ciclos não exibem a fácies $\mathrm{Sr}$, sugerindo rápido decaimento do fluxo e deposicão de lama diretamente sobre dunas subaquáticas. A presença da fácies $\mathrm{P}$ diretamente sobre a fácies Sh mostra a deposição de lama sobre leito plano de regime de fluxo superior, sugerindo um decaimento ainda mais rápido do fluxo. A ausência da fácies $\mathrm{P}$, quando ocorre, provavelmente indica erosão pelo ciclo subsequente. A presença de estratificações cruzadas recumbentes sugerem rápidas taxas de deposição e fluxos com fortes oscilações de potência.

No sentido de se montar um quadro mais acurado do contexto deposicional da unidade estudada, foi construído um fotomosaico abrangendo toda a extensão do afloramento estudado (Fig. 6). A técnica aqui utilizada (análise da arquitetura deposicional) é mais eficaz e completa que a abordagem através de colunas verticais pois possibilita, além da análise dos padrões de empilhamento vertical, um estudo das relações laterais entre as fácies e das suas variações internas. Assim, a análise da arquitetura deposicional permite a verificação das relações espaciais entre corpos ou elementos deposicionais, a definição e caracterização das superficies limites dos mesmos, bem como, em conjunto com a análise de paleocorrentes, permite o estabelecimento de padrões de variações na direção proximal/distal.

A análise da arquitetura deposicional ou análise tridimensional de afloramentos baseia-se em dois conceitos básicos interrelacionados (Miall 1988): 1) O primeiro é o conceito de "escala arquitetural". Depósitos sedimentares são compostos por assembleias de fácies que ocorrem em variadas escalas, desde pequenas ripples individuais até pacotes produzidos por todo um sistema deposicional, podendo estes ser formalizados em uma hierarquia de escalas. Unidades deposicionais para cada escala hierárquica são originadas em resposta a processos sedimentares que ocorrem, da mesma forma, em uma escala de 
tempo particular, sendo separadas por superficies limitantes também hierarquicamente escalonadas. A Tabela 2 sintetiza as características e o significado das diferentes superfícies dentro da escala hierárquica. 2) O segundo conceito é o de "elementos arquiteturais" (Fig. 7), que correspondem a litossomas caracterizados por sua geometria, assembleia de fácies e escala, constituindo o produto deposicional de processo ou gama de processos característicos do sistema deposicional.

A mais notável e importante característica que pode ser obtida através da análise do fotomosaico é uma significativa e rápida diminuição na definição das superfícies limitantes e, consequentemente, dos elementos deposicionais na direção partindo da Fig. 6a até a Fig. $6 d$ (220 040); direção esta que praticamente coincide (diferença de apenas $22^{\circ}$ ) com a direção proximal/distal, obtida através da análise das paleocorrentes (vetor médio - 018, ver Fig. 8). É também clara a boa continuidade lateral das superfícies e seus baixos relevos. Estas características são de grande importância na caracterização do sistema deposicional relativo ao pacote estudado, discutida adiante.

Superfícies de três categorias hierárquicas (ver Tabela 2) podem ser reconhecidas neste afloramento $\left(1^{\mathrm{a}}, 2^{\mathrm{a}} \mathrm{e} 4^{\mathrm{a}}\right.$ ordens), sendo duas delas claramente visíveis no fotomosaico da Fig. $6\left(2^{\mathrm{a}}\right.$ e $4^{\mathrm{a}}$ ordens $)$. As superfícies de $4^{\mathrm{a}}$ ordem limitam os elementos deposicionais chave do pacote estudado, os ciclos de decaimento progressivo de inundação. $\mathrm{O}$ empilhamento destes ciclos é caracterizado por storeys de corpos tabulares de grande continuidade lateral, cada qual composto por produtos depositados durante o decaimento progressivo de um evento deposicional de inundação. Uma delgada camada pelítica fruto de acresção vertical (mud drape) normalmente capeia os ciclos de decaimento progressivo de inundação (ver Figs. 4 e 5), tornando de fácil reconhecimento das superfícies de $4^{\mathrm{a}}$ ordem, tanto no campo quanto no fotomosaico da Fig. 6. As superfícies de $4^{\mathrm{a}}$ ordem, notadamente de baixo relevo e grande continuidade lateral, mostram em alguns casos um caráter nitidamente erosivo, quando truncam cosets do ciclo de inundação inferior. Bons exemplos são vistos no fotomosaico da Fig. 6a na porção à direita da localização da seção vertical da Fig. 4a, constituindo a segunda e a terceira superfícies (de cima para baixo). A terceira superficie trunca, inclusive, a quarta superficie, tendo removido por completo os depósitos do ciclo de inundação entre ambas.

As superfícies de $2^{\mathrm{a}}$ ordem, também facilmente caracterizáveis tanto no campo quanto no fotomosaico da Fig. 6, são definidas pelo contato entre cosets, na maior parte dos casos, compostos por sets de fácies Sh e St/Sp. Algumas superficies de $2^{\mathrm{a}}$ ordem ocorrem separando sets da fácies $\mathrm{St} / \mathrm{Sp}$ de sets da fácies $\mathrm{Sr}$. Alguns contatos, quando não ocorre a fácies $\mathrm{P}$ cobrindo a superfície, são de difícil caracterização quanto a que ordem hierárquica pertencem. Os cosets definidos pelas superfícies de $2^{\mathrm{a}}$ ordem são lenticulares com grande razão extensão lateral/espessura, exibindo adelgaçamento nas suas extremidades, neste caso mostrando relacionamento lateral com outro cosets através de compensação de espessura. Superficies de $\mathrm{l}^{\mathrm{a}}$ ordem, não detectáveis no fotomosaico, podem ser definidas no campo separando sets de estratos cruzados da fácies $\mathrm{St} / \mathrm{Sp}$. Como já explicitado anteriormente, as superfícies perdem definição em direção a porções mais distais do afloramento, onde não podem mais ser distinguidas umas das outras. Superficies de $3^{\mathrm{a}}$ ordem, por definição (ver Tabela 2 ), ocorrem dentro de macroformas (sensu Jackson 1975). Desta forma, a não caracterização de macroformas na sucessão estudada implica automaticamente na inexistência de superficies de $3^{\mathrm{a}}$ ordem.

Três elementos arquiteturais podem ser reconhecidos como componentes dos ciclos de decaimento progressivo de inundação: LS Lençol de areia laminado, SB - Formas de leito arenosas e OF Depósitos finos de planície de inundação. O elemento $L S$ - Lençol de areia laminado, caracteristicamente com geometria tabular e alta razão extensão lateral/espessura, ocorre na base destes ciclos (Fig. 6). São limitados na base sempre por superfícies de $4^{\mathrm{a}}$ ordem, sendo compostos por produtos de enxurradas em lençol sob regime de fluxo superior (fácies Sh). Como o decaimento energético da inundação e instalação de condições sob regime de fluxo inferior, formas de leito arenosas (dunas 3-D e 2-D) se desenvolveram no leito, construindo o elemento $\mathrm{SB}$-Formas de leito arenosas. Caracterizado por alta variedade geométrica (Miall 1985,1988). Este elemento é identificado no afloramento estudado por corpos lenticulares com altas razões extensão lateral/espessura (Fig. 6). Compostos por coset de fácies $\mathrm{St} / \mathrm{Sp}$, os elementos SB são normalmente limitados na base e no topo por superfícies de $2^{\mathrm{a}}$ ordem, exceto onde falta o elemento LS na base do ciclo de inundação, quando o elemento SB é limitado por uma superfície basal de $4^{\mathrm{a}}$ ordem (ver Fig. 4). O elemento $O F$ - Depósitos finos de planicie de inundação ocorre como delgados mud drapes (fácies P)

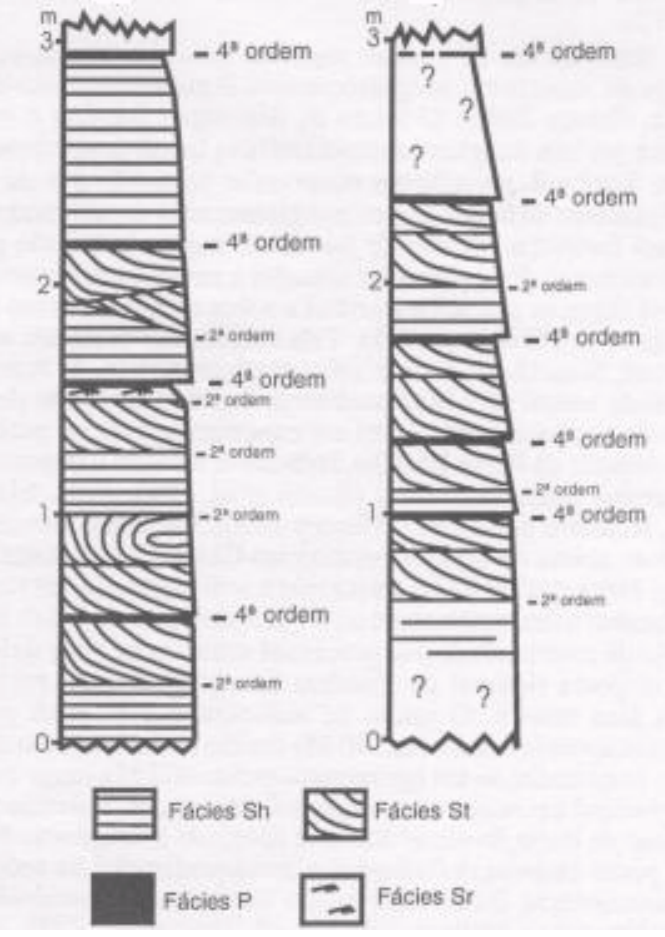

a)

b)

Figura 4 - Seções verticais levantadas no afloramento estudado. Ver Tabela 2 para significado hierárquico das superficies limitantes. As seções encontram-se locadas no fotomosaico da figura 6.

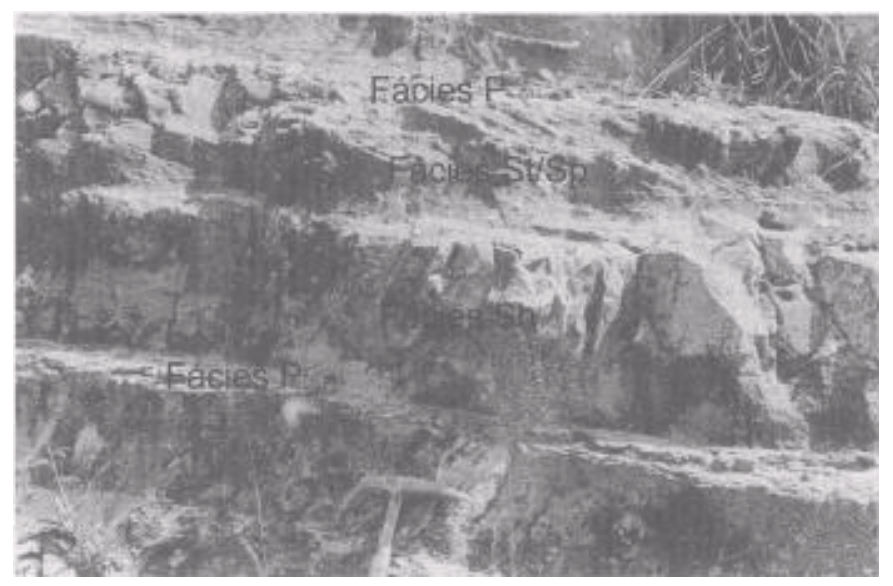

Figura 5 - Fotografia de detalhe mostrando ciclo de decaimento progressivo de inundação composto por fácies Sh na base, seguida de fácies St/Sp, terminando com uma delgada capa pelítica da fácies $P$.

capeando os ciclos de inundação, indicando o completo abatimento destes.

Na porção mais distai do afloramento (Fig. 6d), os elementos arquiteturais, as superfícies que os limitam ou os compartimentam internamente, perdem por completo a definição, podendo ser reconhecidos apenas sets das fácies que compõem o afloramento. Estas fácies ocorrem na forma de corpos delgados, tabulares a lenticulares e lateralmente extensos, complexamente inter-relacionados.

PALEOCORRENTES Um total de 36 medidas de paleocorrentes foi coletado no afloramento estudado (ver Fig. 6 para algumas localizações), através do mergulho de foresets de estratificações cruzadas da fácies $\mathrm{St} / \mathrm{Sp}$. O resultado mostrou um padrão essencial- 
Tabela l-Fácies presentes na seção estudada (códigos modificados de Miall 1978).

\begin{tabular}{|c|c|c|}
\hline cóbIGo & CARACTERISTICAS & INTERPRETACCĀO \\
\hline Sh & Arenitos com estratificação/laminação & $\begin{array}{l}\text { Enxurradas em lencol em regime de fluxo } \\
\text { sunerior }\end{array}$ \\
\hline $\mathrm{Su} / \mathrm{Sp}$ & Arenitos com estratificacão cruzada & Migração de dunas subaquáticas em regime de \\
\hline $\mathrm{Sr}$ & Arenitos com laminação cruzada & $\begin{array}{l}\text { fluxo inferior } \\
\text { Migracãa de ripples de corrente }\end{array}$ \\
\hline $\mathbf{P}$ & Pelitos & Depósitos de acreção vertical \\
\hline
\end{tabular}

Tabela 2 - Hierarquia de superficies limitantes (modificado de Miall 1988, 1990 e Soegaard 1990).

\begin{tabular}{|c|c|c|}
\hline $\begin{array}{l}\text { HIERARQUIA DE } \\
\text { SUPERFICIES }\end{array}$ & DEFINICÃO & Significado \\
\hline $1^{2}$ orden & $\begin{array}{l}\text { Definem sets, ocoitendo dentro de } \\
\text { depósitos de mesoformas ou } \\
\text { microfomas }\end{array}$ & $\begin{array}{l}\text { Representam sedimentaçà̃o continua de un } \\
\text { trem de formas de leito similares, sem ou } \\
\text { com pouca erosão associada }\end{array}$ \\
\hline $2^{2}$ ordem & $\begin{array}{l}\text { Definem cosets, ou grupos de } \\
\text { mesofomas on mieroformas }\end{array}$ & $\begin{array}{l}\text { Indicam mudanças nas condiços ou direçăo } \\
\text { do tluxo, mas năo significante intervalo de } \\
\text { tempo. Fácies acima e abaixo săo diferentes, } \\
\text { mas a superficie năo e marcada por erosao } \\
\text { significativa }\end{array}$ \\
\hline $3^{\text {nn }}$ ordem & $\begin{array}{l}\text { Representam superficies erosivas } \\
\text { dentro de macroformas }\end{array}$ & $\begin{array}{c}\text { Indican mudança de estágio ou orientaça } \\
\text { de formas de leito dentro da macrofomma. As } \\
\text { assembléias de fácies acima e abaixo săo } \\
\text { similares }\end{array}$ \\
\hline $4^{2}$ ordem & $\begin{array}{l}\text { Definem elementos deposicionais } \\
\text { como "storeys" ou macroformas }\end{array}$ & $\begin{array}{l}\text { Indicam mudança no estilo de sedimentaçăo. } \\
\text { Facies acima e abaixo săo nomaimente } \\
\text { diferentes: se similares, ed dificil a distinçăo } \\
\text { de superficies de } 3^{3} \text { ordem }\end{array}$ \\
\hline $5^{n}$ ordem & $\begin{array}{l}\text { Definem unidades deposicionais } \\
\text { maiores como "sand sheets" ou } \\
\text { complexos de preenchinento de canais }\end{array}$ & Pode ser caracterizada em subsuperficie \\
\hline $6^{3}$ ordem & $\begin{array}{l}\text { Englobam depósitos de todo urn } \\
\text { sistema deposicional }\end{array}$ & $\begin{array}{l}\text { Definem unidades estratigráficas como } \\
\text { membros ou associaçoes de fácies }\end{array}$ \\
\hline
\end{tabular}

mente unidirecional (direção NNE, vetor médio $=018$ ) com baixa dispersão (Fig. 8).

\section{PETROLOGIA SEDIMENTAR E PROVENIÊNCIA Em}

lâmina delgada, a rocha apresenta textura elástica, granulometria fina, selecionamento moderado a bom. Ocasionalmente, observa-se uma heterogeneidade textural devido à presença de pseudo matriz gerada pelo esmagamento de grãos dúcteis do arcabouço da rocha (Fig. 9a). O empacotamento (packing) é do tipo fechado, predominando contatos côncavo-convexos e suturados entre os grãos, com ausência de porosidade. Observam-se, entretanto, alguns contatos do tipo flutuante devido à intensa cimentação por quartzo.

O quartzo é o principal constituinte da rocha, caracterizando a mesma como quartzo-arenito. Predomina o tipo comum com leve extinção ondulante. Subordinadamente ocorrem o quartzo metamórfico, rico em inclusões de micrólitos aciculares e o quartzo de veio, caracterizado pelas nuvens de poeira. A presença de sobrecrescimentos arredondados (Fig. 9b) permite inferir processos de reciclagem. O feldspato é extremamente raro, e exibe, mormente ao longo dos planos de clivagem e das bordas dos grãos, uma forte substituição por sericita (Fig. 9c). Registra-se ainda a pseudomorfose por caulinita (Fig.9d). Estes processos de substituição impedem uma determinação segura do tipo de feldspato. A assembleia de pesados é constituída por zircão, turmalina, rutilo e minerais opacos.

Apesar do limitado número de lâminas descritas, o estudo petrográfico permitiu o reconhecimento de algumas fases diagenéticas e a sua correlação com os estágios eo, meso e telodiagenéticos. A eodiagênese foi caracterizada por uma fase aditiva de infiltração mecânica de arguas sob a forma de delgadas películas que dispõem-se tangencialmente à superfície dos grãos detríticos (Fig. 9e). Esta fase diagenética é controlada pelo modelo deposicional, sendo bem mais intensa em amostras de fácies proximais que naquelas relacionadas à fácies mais distais. Sob condições mesodiagenéticas ocorreram a compactação mecânica, compactação química, cimentação por quartzo e autigênese de pirita. A compactação mecânica promoveu a rotação de grãos rígidos e o esmagamento de grãos dúcteis, gerando pseudo matriz e reduzindo a porosidade primária da rocha (Fig. 9a). A compactação química é evidenciada pelo contato suturado que se observa entre alguns grãos devido a dissolução por pressão. A cimentação por quartzo constitui a fase diagenética volumetricamente mais importante, perfazendo o cimento de quartzo cerca de $15 \%$ da rocha. Ele ocorre sob a forma de sobrecrescimentos que se distinguem dos grãos detríticos, com os quais mantêm continuidade ótica, por uma finíssima película de óxidos de ferro e minerais de argila (Fig. 9f). Esta fase diagenética foi responsável pela redução intensa da porosidade da rocha. A solução por pressão constituiu provavelmente a fonte da sílica necessária para a cimentação. Como fase diagenética tardia registra-se a ocorrência de pirita, que forma cristais euédricos dispostos no espaço poroso da rocha. Durante a telodiagênese ocorreram a oxidação de minerais opacos e a intensa caulinização dos feldspatos.

Os dados de proveniência da sucessão estudada indicam as rochas da Megasseqüência Espinhaço como possível fonte dos sedimentos. Tal fato é reforcado pelos dados de paleocorrente e dispersão de sedimentos, discutidos a seguir, indicando ter sido a área fonte um alto situado na atual Serra da Água Fria. Os dados de proveniência obtidos através de clastos dos diamictitos Jequitaí (Hercos 2000) corroboram somente em parte esta interpretação. A maioria dos níveis de diamictito contêm apenas clastos de arenitos, petrograficamente compatíveis com a Megasseqüência Espinhaço. Alguns níveis que contêm clastos de carbonato dolomítico poderiam também ser provenientes da Megasseqüência Espinhaço, posto que rochas petrograficamente similares ocorrem no topo desta unidade. Em termos de proveniência, merecem atenção especial os níveis que apresentam clastos de granitóides do embasamento, sendo que alguns são compostos unicamente por esta litologia (Hercos 2000).

\section{SISTEMA DEPOSICIONAL E PALEOGEOGRAFIA As}

feicões sedimentares e petrológicas do depósito no afloramento estudado, aqui descritas e discutidas, indicam, em conjunto, uma deposição relacionada a processos fluviais. A ausência de feições geomorfológicas bem definidas como canais, macroformas e planícies de inundação, a uniformidade (baixa complexidade) da associação de fácies observada, a alta razão largura/profundidade constatada para os elementos deposicionais constituintes do pacote estudado, bem como o padrão de paleocorrentes medido (unidirecional com baixíssima dispersão), indicam que o sistema deposicional foi provavelmente uma 


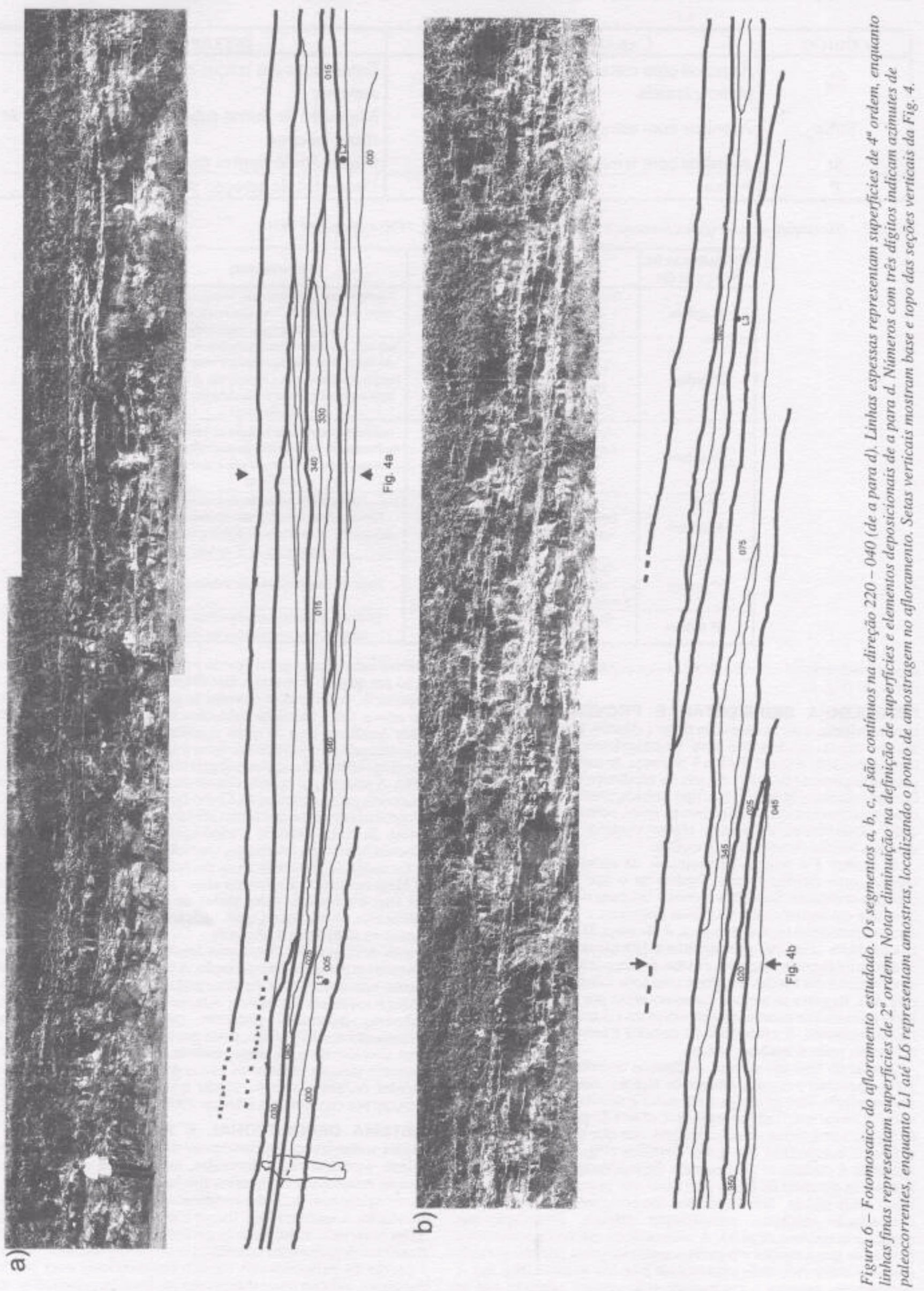




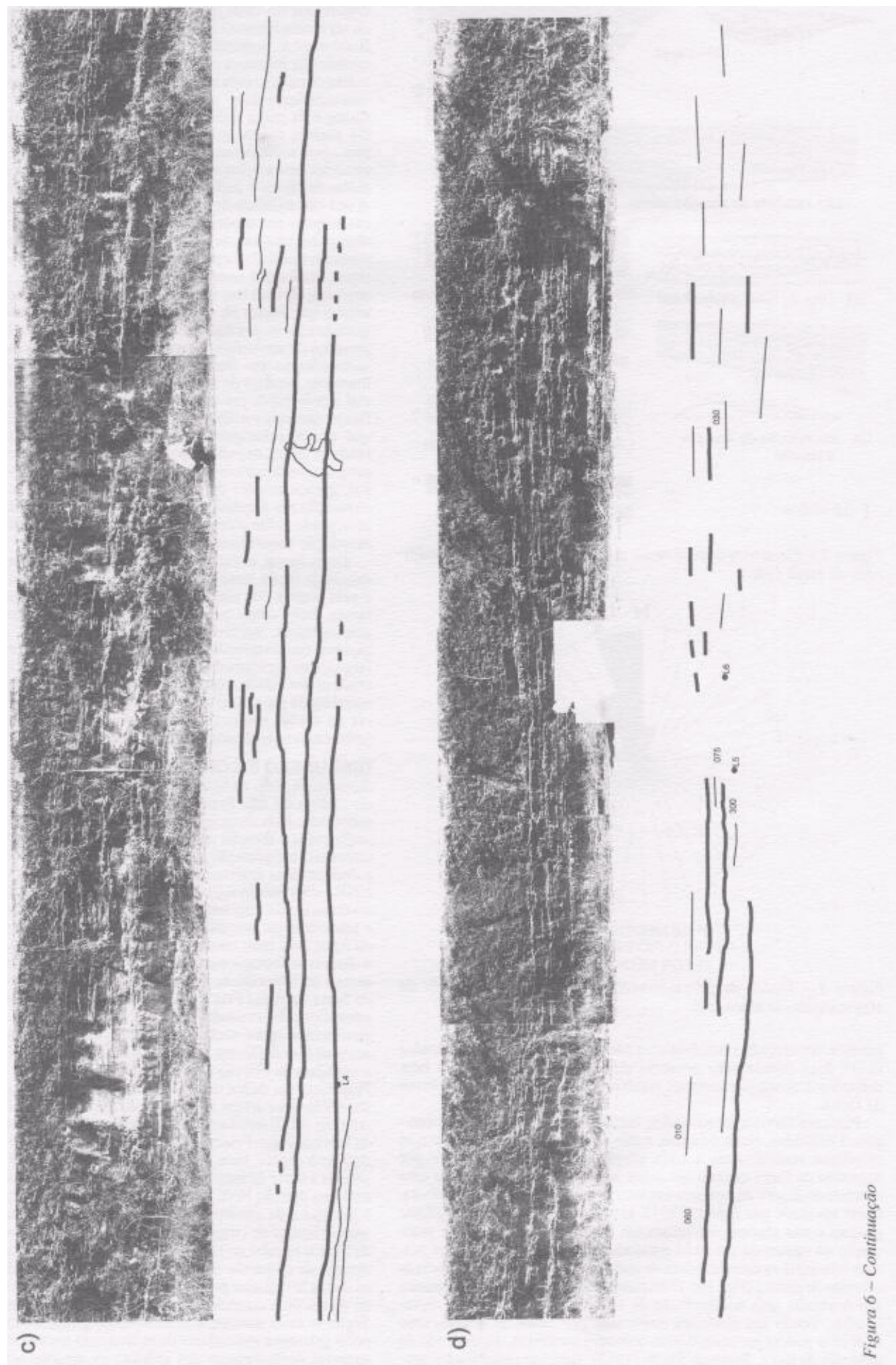



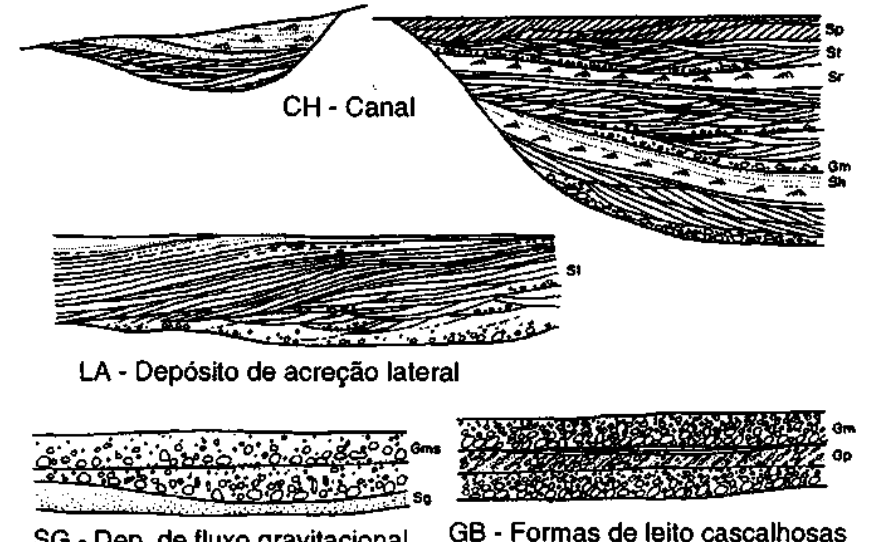

SG - Dep. de fluxo gravitacional

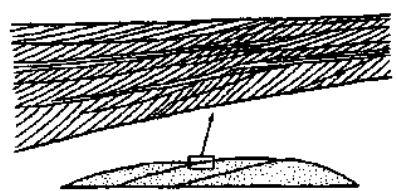

DA - Macroforma de acreçąo a jusante

$[0,2 \cdot 2,0 \mathrm{~m}$

Figura 7 -Elementos arquiteturais para depósitos aluviais (modificado de Miall 1988).

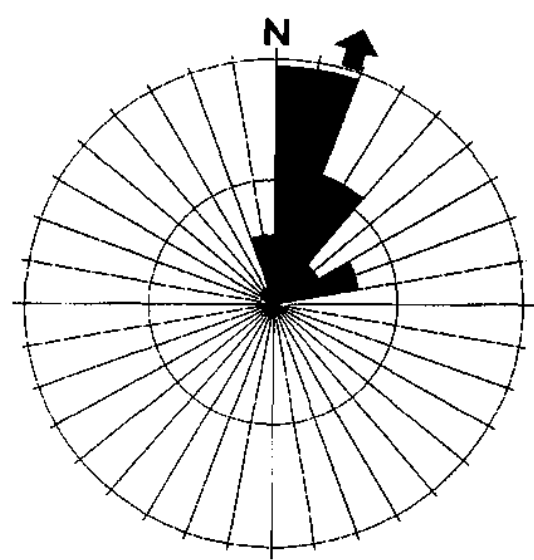

$N^{\circ}$ DE MEDIDAS $=36$

CÍRCULO EXTERNO $=40 \%$

VETOR MÉDIO = 018

Figura 8 - Dados de paleocorrente do afloramento estudado da Megasseqüencia Macaúbas.

planície entrelaçada (braidplain) e não um rio entrelaçado (braided river). Rios entrelaçados possuem elementos geomorfológicos bem definidos e, consequentemente, resultam em arranjos mais complexos de fácies.

Planícies fluviais entrelaçadas, caracterizadas por redes de canais pouco definidos, rasos e largos, e que se associam lateralmente e se empilham verticalmente a cada evento agradacional, ocorrem por expansão de fluxo quando um leque aluvial, um rio braided ou uma corrente de degelo desemboca em uma planície deposicional. Embora, como apontado por Smith (1985), as semelhanças entre braidplains glaciais e não glaciais suplantam em muito suas diferenças, a associacão no campo da sucessão estudada com diamictitos Jequitaí permite interpretá-la como produto de uma planície entrelaçada associada a frentes de geleira (Fig. 10). Planícies entrelaçadas de frente de geleira são formadas pela coalescência de sistemas de canais rasos entrelaçados. Tendo sua dinâmica controlada por ciclos de degelo, seus depósitos podem ser cascalhosos, arenosos ou mistos, dependendo da distância da fonte. Segundo Smith (1985), sistemas entrelaçados pro- glaciais (também denominados de sandur, plural sondar) podem ser confinados em vales (p.ex., Markarfljotsandur, Islândia; Bluck 1974) ou ser essencialmente desconfinados (p. ex. Skeidarársandur, Islândia; Boothroyd \& Nummdal 1978). Os sondar desconfinados (conhecidos também na literatura por outwash plains) são caracterizados por uma malha de canais rasos entrelaçados, notadamente instáveis, que mudam continuamente suas posições em resposta à alta variabilidade dos fluxos e da carga sedimentar, típico do regime dos ciclos de degelo. Da mesma forma que as braidplains em contexto não glacial, os processos sedimentares nas planícies de degelo são fortemente influenciados pelo caráter não confinado do sistema, resultando em assembleias de fácies e padrão de paleocorrentes relativamente uniformes. A alta sazonalidade dos ciclos de degelo também imprime características próprias aos depósitos resultantes. A principal evidência do caráter altamente sazonal dos fluxos geradores dos ciclos de degelo na sucessão estudada é a presença de capas de lama (muddrapes) nos seus topos, indicando completo abatimento do fluxo, e de produtos de descarga elevada nas suas bases (Fácies Sh). Tunbridge $(1981,1984)$ mostra que Fácies Sh não ocorre tipicamente em correntes perenes e, quando ocorre, normalmente não está presente na base dos ciclos. A presença de estratificações cruzadas recumbentes indica altas taxas de sedimentação em fluxos rápidos sob significativa tensão de cisaIhamento, capazes de depositar o sedimento saturado em água intersticial e deformá-lo em estado liquefeito (Allen 1984), o que é típico de fluxos sazonais e efémeros. A infiltracão mecânica de argila (Fig. 9e), que ocorre principalmente nas fácies mais proximais do sistema, também indica deposição por processos fluviais através de fluxos em progressivo decaimento de energia. A presença de pseudo matriz (Fig. 9a), gerada através de intraclasto argiloso, indica provavelmente a exposição e o retrabalhamento de capas de lama de ciclos anteriores, reforcando assim o caráter efềmero dos fluxos geradores dos ciclos de inundação observados.

Desta forma, as características da sucessão estudada, indicadas pelo estudo de fácies sedimentares, pelas suas características petrográficas e pela análise dos elementos arquiteturais e de suas superficies limitantes, bem como pela sua associação no campo com depósitos glaciogênicos, sugerem, em conjunto, deposição através de fluxos rápidos em progressivo decaimento energético, em canais rasos e largos, que rapidamente perdem a definição na direção distai, suportando assim a interpretação do sistema deposicional como uma planície entrelaçada proglacial (outwash plain), caracterizada pela coalescência de canais instáveis, alimentados por fluxos altamente sazonais (efêmeros) relacionados a ciclos de degelo.

DISCUSSÃO E CONCLUSÕES A caracterização de depósitos de outwash plain na base da Megasseqüência Macaúbas nos domínios do Cráton do São Francisco, associados aos diamictitos Jequitaí e, sobretudo, suas características paleogeográficas tais como fonte dos sedimentos e direção de dispersão, acrescentam informações importantes na interpretação do sistema tectônico da Bacia Macaúbas. As paleocorrentes analisadas (Fig. 8) indicam sentido de transporte para $\mathrm{NNE}$ (vetor médio $=018$, ver Fig. 8). Estes dados, quando analisados no contexto de uma análise mais regional das unidades glaciogênicas e associadas da base da Megasseqüêencia Macaúbas na região da Serra da Água Fria, indicam um sistema compartimentado, com alimentação e dispersão tectono-controlados (Hercos 2000). Dados de paleocorrente e de dispersão de geleira (Hercos 2000), obtidos na encosta oeste da Serra da Agua Fria a sul da cidade de Jequitá (Fig. 1) através de estratificações cruzadas em arenitos Macaúbas e de estrias em pavimentos sobre rochas Espinhaço, mostram que os diamictitos e arenitos (ver seção em Hercos \& Martins-Neto 1997) provêm da serra e avançam na direção oeste, em direção ao interior do Cráton do São Francisco. Os dados de paleocorrente da sucessão de outwash plain, abordada neste artigo, e da região da borda oeste da Serra da Água Fria (Hercos 2000) mostram, em conjunto, a existência de um alto na região da Serra da Agua Fria que, sob a atuação de geleiras e de ciclos sazonais de gelo e degelo, teria fornecido os sedimentos para uma região baixa situada a oeste da mesma. O sistema de outwash plain desenvolveu-se então na direção NNE, através de depósitos de diamictitos associados a geleiras e de arenitos fluvio-glaciais, ambos alimentados por áreas altas oriundas da compensação isostática em conjunto com a rotação de blocos ligados ao regime de subsidência do sistema extensional. A direção de dispersão de sedimentos aqui obtida (NNE) coincide com os dados levantados por Gravenor \& Monteiro (1983) em afloramento de diamictitos associado à mesma exposição estudada neste trabalho. Segundo estes autores, a orientação de grandes blocos transportados pelas geleiras e indicadores de movimento em planos de cisalhamento sugerem deslocamento das geleiras na direção norte-nordeste. Esta 

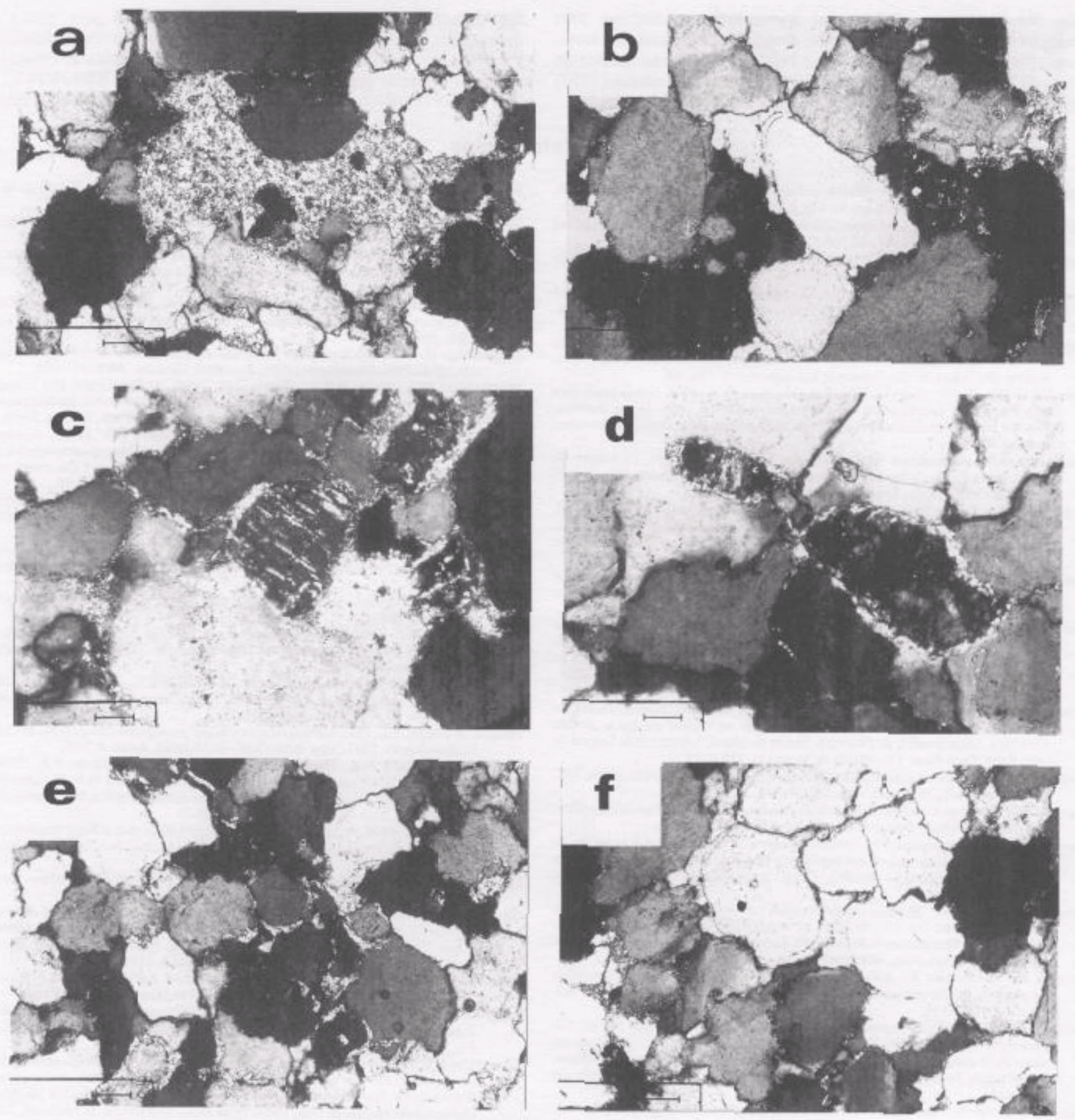

Figura 9 - a) Pseudo matriz gerada por esmagamento de intraclasto argiloso, b) Sobrecrescimento arredondado de quartzo sugerindo reciclagem de grãos, c) Grão de feldspato intensamente sericitizado. d) Pseudomorfose de feldspato por caulinita. e) Argila mecanicamente infiltrada, f) Cimentação intensa por quartzo. Nicóis cruzados em todas as fotos. Altura da foto 0,9 mm em $a, b, e, f ; 0,4 \mathrm{~mm} \mathrm{em} c, d ; 0,2$ mm em $\mathrm{g}$.

paleogeografia, conforme modelo proposto por Martins-Neto et al (1997a), estaria ligada à tectônica extensional riftogênica do início do Neoproterozóico, que levou ao desenvolvimento da Bacia Macaúbas/Salinas.

Outros autores (p. ex., Uhlein 1991, Trompette 1994, Uhlein et al. 1995) admitem a deposição dos sedimentos glaciogênicos em um contexto extensional ligado ao desenvolvimento da Bacia Macaúbas/Salinas. Entretanto, estes autores consideram que a porção localizada hoje sobre o Cráton do São Francisco, correspondente à região de Jequitaí, não teria sido afetada pela tectônica extensional, sendo os depósitos glaciogênicos desta região relativos a uma glaciação continental que teria alimentado a bacia posicionada mais a

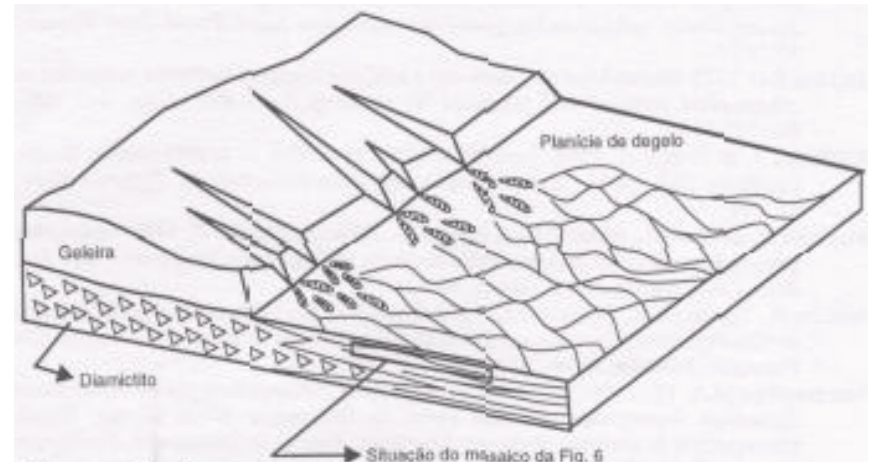

Figura 10 - Reconstrução paleogeográfica esquemática da planície proglacial entrelaçada da base da Megasseqüencia Macaúbas (desenho sem escala). 
leste. No entanto, os dados aqui apresentados evidenciam uma glaciação de altitude com, inclusivive, dispersão de sedimentos localmente (borda oeste da Serra da Água Fria) em direção ao interior do Cráton do São Francisco e dai' para NNE. Gravenor \& Monteiro (1983) também sugeriram diferentes direções para a dispersão de geleiras.
Agradecimentos Ao colega P.T.A. Castro pela crítica no manuscrito, à FAPEMIG pela ajuda financeira através de Auxílio à Pesquisa (processo CEX 895/95) e ao CNPq por Bolsa de Produtividade em Pesquisa para o primeiro autor (processo 300404/94-8). A dois revisores anônimos da RBG pelas sugestões e críticas ao original.

\section{Referências}

Allen J.R.L. 1984. Sedimentary Structures:Their Character and Physical Basis. Developments in Sedimentology 30, Vol 1, 2nd ed, Elsevier, Amsterdam, $593 \mathrm{p}$

Ashley G.M. 1990. Classifieation of large-scale subaqueous bedforms:a new look at an old problem. J. Sediment. Petrol., 60:160-172

Bluck B.J. 1974. Structure and directional properties of some valley sandur deposits in southern Iceland. Sedimentology, 21:533-554.

Boothroyd J.C. \& Nummedal D. 1978. Proglacial braided outwash:a model for humid alluvial-fan deposits. In: A.D. Miall (ed.) Fluvial Sedimentology. Can. Soe Petrol. Geol. Memoir, 5:641-668.

Braun O.P.G., Martins, M., Oliveira W.J. 1993. Continuidade da sequências rifeanas sob a Bacia do São Francisco constatada por levantamentos geofísicos em Minas Gerais. II Simp. Do Cráton do São Francisco, Salvador, Anais, 164-166

Braun O.P.G., Martins M., Paula L., Silva P.R., Medeiros R. A. 1996. Novas bases para uma reavaliação estratigráfica das sequências mapeadas como Grupo Paranoá, Traíras e Bambuí, em Goiás e Minas Gerais. SBG, Congr. Brás. Geol., 39, Salvador, Anais, 5:506-509.

Brito Neves B.B., van Schmus W.R., Babinsky M., Sabin T. 1993. O evento de magmatismo de 1,0 Ga nas faixas móveis ao norte do Cráton do São Francisco. II Simp. Do Cráton do São Francisco, Salvarod, Anais, 243-245.

Buchwaldt R., Toulkeridis T., Babinski M., Noce C.M., Martins-Neto M. A., Hercos C.M. 1999. Age determination and age related provenance analysis of the Proterozoic glaciation event in central eastern Brazil. II South American Symp. on Isotope Geology, Córdoba, Argentina, setembro 1999, pp. 387-390. Castro P.T.A. 1997. O

conglomerados da borda SW do Craton do São Francisco junto à porção S da Faixa Brasilia:sedimentologia e relações estratigráflcas com as rochas do Grupo Bambuí. IG/Univ. de Brasília, Brasília, Tese de Doutorado, $264 \mathrm{p}$

Castro P.T.A. \& Dardenne M.A. 1995. O conglomerado Samburá (Grupo Bambuí, Proterozóico Superior) e rochas sedimentares associadas no flanco leste da Seira da Pimenta, SW de Minas Gerais: sedimentação associada à inversão tectônica na porção meridional externa da Faixa Brasília. V SNET -Simp. Nac. Est. Tect., Gramado, RS, Anais, 274-276.

Chiavegatto J.R.S. 1992. Análise estratigráfica das sequências tempestíticas da Formação Três Marias (Proterozóico Superior), na porção meridional da Bacia do São Francisco. Departamento de Geologia, Escola de Minas, Universidade Federal de Ouro Preto, Ouro Preto, Dissertação de Mestrado, $216 \mathrm{p}$

Dardenne M. A. 1978. Síntese sobre a estratigrafia do Grupo Bambuí no Brasil central. SBG Cong. Brás. Geol., 30, Recife, Anais, 2:597-610.

Dupont H. 1995.0 Grupo Conselheiro Mata no seu quadro paleogeográfico e estratigráfico. Boi. Soe. Brás. Geol., Núcleo Minas Gerais, 13:9-10.

Dupont H. 1996. O Supergrupo São Francisco entre a Serra do Cabral e as serras do Espinhaço e de Minas: estudo estratigráfico e estrutural e relacões de contato com o Supergrupo Espinhaço. In:SBG, Cong. Brás. Geol, 39, Salvador, Anais, 5:489-493.

Espinoza J.A.A. 1996. Sistemas deposicionais e relações estratigráflcas da Tectonosseqüencia Conselheiro Mata, na borda leste da Serra do Cabral, Mina Gerais, Brasil. Departamento de Geologia, Escola de Minas, Universidade Federal de Ouro Preto, Ouro Preto, Dissertação de Mestrado, $66 \mathrm{p}$

Gravenor C.P. \& Monteiro R.L.B.P. 1983. Ice-thrust features and a possible intertillite pavement in the Proterozoic Macaúbas Group, Jequitaí área, Minas Gerais, Brazil. J. Geol., 91:113-116.

Hercos C.M. 2000. Evolução tectono-estratigráfica da Bacia Neoproteroióica do São Francisco, na região entre Pirapora e a Serra da Agua Fria, $M G$, com base em dados de campo e sísmica de reflexão. Departamento de Geologia, Escola de Minas, Universidade Federal de Ouro Preto, Ouro Preto, Dissertação de Mestrado, em preparação.

Hercos C.M. \& Martins-Neto M.A. 1997. Considerações sobre os Supergrupos Espinhaço e São Francisco na borda oeste da Serra da Água Fria (MG). Boi. Soe. Brás. Geol. Núcleo Minas Gerais, 14:19-21.

Hubbart R.J., Pape J., Roberts D.G. 1985. Depositional sequence mapping as a technique to establish tectonic and stratigraphic framework and evaluate hydrocarbon potential on a passive continental margin. In: O.R. Berg \& D. Woolverton (eds.) Seismic StratigraphylI.-Anlntegrated Approach. Am. Assoe. Petrol. Geol. Memoir 39:79-91

Jackson R.G. 1975. Hierarchical attributes and a unifying model of bedforms composed of cohesionless material and produced by shearing flow. Buli. Geol. Soe. Am. 86:1523-1533.

Karfunkel J. \& Hoppe A. 1988. Late Proterozoic glaciation in central-eastern Brazil: Synthesis and model. Palaeogeography, Palaeoclimatologv, Palaeoecology, 65:1-21.

Machado N., Schrank A., Abreu F.R., Knauer L.G., Almeida Abreu P. A. 1989. Resultados preliminares da geocronologia $\mathrm{U} / \mathrm{Pb}$ na Serra do Espinhaço Meridional. Boi. Soe. Brás. Geol., Núcleo Minas Gerais, 10:171-174.

Martins M., Teixeira L.B., Braun O.P.G. 1993. Considerações sobre a estratigrafia da Bacia do São Francisco com base em dados de subsuperfície. II Simp. do Cráton do São Francisco, Salvador, Anais, 167-169.

Martins-Neto M.A. 1993. The sedimentary evolution ofa Proterozoic r ift basin:the basal Espinhaço Supergroup, southern Serra do Espinhaço, Minas Gerais, Brazil. Universidade de Freiburg, Freiburg, Alemanha, Tese de Doutoramento, Freiburger Geowiss. Beitr., Band 4, 155 p.

Martins-Neto M.A. 1994. Braidplain sedimentation in a Proterozoic rift basin:the São João da Chapada Formation, southeastern Brazil. Sediment. Geol., 89:219-239.
Martins-Neto M. A. 1995a. A evolução tectônica da Bacia Espinhaço no Estado de Minas Gerais. V SNET - Sirrip. Nac. Est. Tect., Gramado, RS, Anais, 287-289.

Martins-Neto M.A. 1995b. Tectono-estratigrafia da Bacia Espinhaco no Estado de Minas Gerais. Boi. Soe. Brás. Geol., Núcleo Minas Gerais, 13:25-27.

Martins-Neto M.A. 1996a. Lacustrine fan-deltaic sedimentation in a Proterozoic rift basin:the Sopa-Brumadinho Tectonosequence, southeastern Brazil. Sedimentary Geology, 106:65-96.

Martins-Neto M.A. 1996b. Aspectos tectono-deposicionais da Tectonosseqüência Galho do Miguel, Bacia Espinhaço (MG), SBG, Cong. Brás. Geol., 39, Salvador, Anais, 5:391-394.

Martins-Neto M. A. 1998.0 Supergrupo Espinhaço em Minas Gerais: registro de uma bacia rift-sag do Paleo/Mesoproterozóico. Rev. Brás. Geociên., 48(2):151-168.

Martins-Neto M.A., Castro P.T.A., Hercos C.M. 1997a. O Supergrupo São Francisco (Neoproterozóico) no Cráton do São Francisco em Minas Gerais. In: Simpósio de Geologia de Minas Gerais, 9, Ouro Preto, Anais..., Ouro Preto, SBG, p. 22-24.

Martins-Neto M.A., Castro P.T.A., Ramos M.L.S., Murta C.R. 1997b. A pseudo discordância angular entre os Superorupos Espinhacco (Mesoproterozóico) e São Francisco (Neoproterozóico) na regiño entre Santa Bárbara e Curimata serra mineira (MG). Boi. Soe. Brás. Geol., Núcleo Minas Gerais, 14:25-26.

Miall A.D. 1978. Lithofacies types and vertical profile models in braided river deposits: a summary. In: A.D. Miall (ed.) Fluvial Sedimentology. Can. Soe. Petrol. Geol. Memoir, 5:597-604.

Miall A.D. 1988. Fácies architecture in clastic sedimentary basins. In: K.L. Kleinspehn \& C. Paola (eds.) New Perspectives in Basin Analysis, Springer-Verlag, Heidelberg, 67-81.

Miall A.D. 1990. Principies of Sedimentary Basin Analysis. 2nd ed., Springer-Verlag, Heidelberg, $668 \mathrm{p}$

Pedrosa-Soares A.C. 1995. Potencial aurífero do Vale do Araçuai, MG:História da exploração, geologia e controle tectono-metamórfico. IG/Univ. Brasília, Brasília Tese de Doutorado $177 \mathrm{p}$

Pedrosa-Soares A.C., Dardenne M.A., Hasui Y., Castro F.D.C., Carvalho M.V.A., Reis A.C. 1994. Mapa Geológico do Estado de Minas Gerais, escala 1: 1.000 .000 e Nota Explicativa, 97 p. COMIG, Belo Horizonte.

Pflug, R. \& Renger, F. E. 1973. Estratigrafia e evolução geológica da margem SE do Cráton Sanfranciscano. SBG Cong. Brás. Geol., 27, Aracaju, Anais, 2:5-19.

Pimentel M.M., Fuck R.A., Dardenne M.A., Silva L.J.H.D., Menezes P.R. 1995. O magmatismo ácido peraluminoso associado ao Grupo Araxá na região entre Pires do Rio e Ipamerí, Goiás: Características geoquímicas e implicações geotectônicas. Simp. Geol. Centro-Oeste, Goiânia, Anais, 68-71.

Romeiro Silva P.C. 1997. A passagem do Mesoproterozóico para o Neoproterozóico no centro-leste do Brasil e o estilo estrutural envolvido. Boi. Soe. Brás. Geol. Núcleo Minas Gerais, 14:9.

Schöll W.U. 1972. Der südwestliche Randbereich der Espinhaço-Zone, Minas Gerais, Brasilien. Geol. Rdsch., 61:201-216.

Silva R.R. 1995. Contribution Io the stratigraphy and paleogeography of the lower Espinhaço Supergroup (Mesoproterozoic) between Diamantina and Gouveia, Minas Gerais, Brazil. Universidade de Freiburg, Freiburg, Alemanha, Tese de Doutoramento, Freiburger Geowiss. Beitr., Band 8,115 p.

Smith N.D. 1985. Proglacial fluvial environments. In: G.M. Ashley; J. Shaw \& N.D. Smith (eds.), Glacial Sedimentary Environments. SEPM Short Course, 16:85-134

Soegaard K. 1990. Fan-delta and braid-delta systems in Pennsylvanian Sandia Formation, Taos Trough, northern New México: depositional and tectonic implications. Geol. Soe. Am. Buli, 102:1325-1343.

Souza Filho R.C. 1995. Arcabouço estrutural da porção externa da Faixa Araçuaí na Serra do Cabral $(M G)$ e o contraste de estilos deformacionais entre os Supergrupos Espinhaço e São Francisco. Departamento de Geologia, Escola de Minas, Universidade Federal de Ouro Preto, Ouro Preto, Dissertaç̃o de Mestrado, 148 p.

Teixeira L.B., Martins M., Braun O.P.G. 1993. Evolução geológica da Bacia do São Francisco com base em sísmica de reflexão e métodos potenciais. II Simp. do Cráton do São Francisco, Salvador, Anais, 179-181.

Trompette R. 1994. Geology of Western Gondwana (2000-500 Ma):Pan-African-Brasiliano Aggregation of South America and África. A.A. Balkema, Rotterdam, $350 \mathrm{p}$.

Tunbridge I.P. 1981. Sandy high-energy flood sedimentation -some criteria for recognition, with an example from the Devonian of SW England. Sediment. Geol., 28:79-96.

Tunbridge I.P. 1984. Fácies model for a sandy ephemeral stream and clay playa complex; the Middle Devonian Trentishoe Formation of North Devon, U.K.. Sedimentology, 31:697-716.

Uhlein A. 1991. Transição cráton-faixa dobrada:exemplo do Cráton do São Francisco e da Faixa Araçuai (Ciclo Brasiliano) no Estado de Minas Gerais. Aspectos Estratigráficos e Estruturais. Inst. de Geociências, Universidade de São Paulo, São Paulo, Tese de Doutoramento, $295 \mathrm{p}$

Uhlein A., Trompette R., Egydio-Silva M. 1995. Rifteamentos superpostos e tectônica de inversão na borda sudeste do Cráton do São Francisco. Geonomos, 3:99-107.

Valeriano C.M. 1992. Evolução tectônica da extremidade meridional da Faixa Brasilia região da Represa de Furnas, sudoeste de Minas Gerais. Univ. São Paulo, São Paulo, Tese de Doutorado, 192 p. 